Supplement of Atmos. Chem. Phys., 18, 10869-10879, 2018

https://doi.org/10.5194/acp-18-10869-2018-supplement

(c) Author(s) 2018. This work is distributed under

the Creative Commons Attribution 4.0 License.

(c) (1)

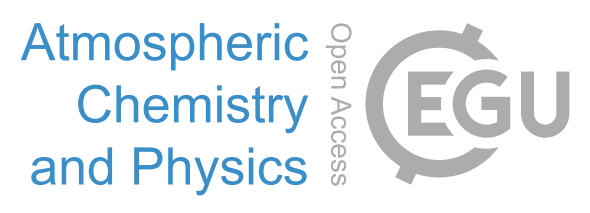

Supplement of

\title{
Does afforestation deteriorate haze pollution in Beijing-Tianjin-Hebei (BTH), China?
}

\section{Xin Long et al.}

Correspondence to: Guohui Li (ligh@ ieecas.cn)

The copyright of individual parts of the supplement might differ from the CC BY 4.0 License. 
19 Table S1 Land use categories in the MCD12Q1 IGBP layer and WRF-CHEM MODIS land 20 use.

\begin{tabular}{|c|c|c|}
\hline \multirow{2}{*}{ Land Cover Category } & \multicolumn{2}{|c|}{ Category number } \\
\hline & WRF-CHEM MODIS & MOD12Q1 \\
\hline Evergreen Needleleaf forest & 1 & 1 \\
\hline Evergreen Broadleaf forest & 2 & 2 \\
\hline Deciduous Needleleaf forest & 3 & 3 \\
\hline Deciduous Broadleaf forest & 4 & 4 \\
\hline Mixed forest & 5 & 5 \\
\hline Closed shrublands & 6 & 6 \\
\hline Open shrublands & 7 & 7 \\
\hline Woody savannas & 8 & 8 \\
\hline Savannas & 9 & 9 \\
\hline Grasslands & 10 & 10 \\
\hline Permanent wetlands & 11 & 11 \\
\hline Croplands & 12 & 12 \\
\hline Urban and built-up & 13 & 13 \\
\hline $\begin{array}{c}\text { Cropland/Natural vegetation } \\
\text { mosaic }\end{array}$ & 14 & 14 \\
\hline Snow and ice & 15 & 15 \\
\hline Barren or sparsely vegetated & 16 & 16 \\
\hline Water & 17 & 0 \\
\hline Wooded Tundra & 18 & $x$ \\
\hline Mixed Tundra & 19 & $x$ \\
\hline Barren Tundra & 20 & $x$ \\
\hline Unclassified & $x$ & 254 \\
\hline Fill Value & $x$ & 255 \\
\hline
\end{tabular}


Table S2 Threshold of the area fractional coverage of green vegetation, minimal and maximal 28 SFz0 used in the coupled unified Noah land-surface model.

\begin{tabular}{|c|c|c|c|c|}
\hline Category No. & Land Cover Category & $\mathbf{G}_{\mathbf{T}}$ & $\mathrm{SFz0}_{\min }$ & $\mathrm{SFz0}_{\max }$ \\
\hline 1 & Evergreen Needleleaf forest & 0.70 & 50 & 50 \\
\hline 2 & Evergreen Broadleaf forest & 0.95 & 50 & 50 \\
\hline 3 & Deciduous Needleleaf forest & 0.70 & 50 & 50 \\
\hline 4 & Deciduous Broadleaf forest & 0.80 & 50 & 50 \\
\hline 5 & Mixed forest & 0.80 & 20 & 50 \\
\hline 6 & Closed shrublands & 0.70 & 1 & 5 \\
\hline 7 & Open shrublands & 0.70 & 1 & 6 \\
\hline 8 & Woody savannas & 0.70 & 1 & 5 \\
\hline 9 & Savannas & 0.50 & 15 & 15 \\
\hline 10 & Grasslands & 0.80 & 10 & 12 \\
\hline 11 & Permanent wetlands & 0.60 & 30 & 30 \\
\hline 12 & Croplands & 0.80 & 5 & 15 \\
\hline 13 & Urban and built-up & 0.10 & 50 & 50 \\
\hline 14 & $\begin{array}{c}\text { Cropland/Natural vegetation } \\
\text { mosaic }\end{array}$ & 0.80 & 5 & 14 \\
\hline 15 & Snow and ice & 0.00 & 0.1 & 0.1 \\
\hline 16 & Barren or sparsely vegetated & 0.01 & 1 & 1 \\
\hline 17 & Water & 0.00 & 0.01 & 0.01 \\
\hline 18 & Wooded Tundra & 0.60 & 30 & 30 \\
\hline 19 & Mixed Tundra & 0.60 & 15 & 15 \\
\hline 20 & Barren Tundra & 0.30 & 5 & 10 \\
\hline
\end{tabular}


Figure S1 Spatial distribution of (a) Organic carbon (OC), (b) Volatile organic compound (VOCs), (c) Nitrogen oxide, and (d) Sulfur dioxide $\left(\mathrm{SO}_{2}\right)$ emission rates in December 2013.

Figure S2 Comparison of the simulated (a) wind direction (wdir), (b) wind speed (wspd), and (c) planetary boundary layer height (PBLH) with the reanalysis data from ECMWF at monitoring sites in BTH from 1 December 2013 to 31 January 2014. The black dots represent the observations, and the red lines denote the reanalysis data. Data are averaged over all monitoring stations in BTH.

Figure S3 Pattern comparisons of simulated (color counters) vs. observed (colored circles) near-surface $\mathrm{PM}_{2.5}$ mass concentrations averaged during each episode. The black arrows indicate simulated surface winds.

Figure S4 Horizontal distribution of near-surface $\mathrm{PM}_{2.5}$ mass concentration changes caused by the afforestation during each episode. The wind field changes are shown in black arrows.

Figure S5 Horizontal distributions of aerosol species mass concentrations and changes due to the afforestation for (a1, a2) organic aerosol (OA), (b1, b2) sulfate $\left(\mathrm{SO}_{4}\right),(\mathrm{c} 1, \mathrm{c} 2)$ nitrate $\left(\mathrm{NO}_{3}\right),(\mathrm{d} 1, \mathrm{~d} 2)$ ammonium $\left(\mathrm{NH}_{4}\right)$, and $(\mathrm{e} 1, \mathrm{e} 2)$ elemental carbon $(\mathrm{EC})$ during the episodes.

Figure S6 Horizontal distributions of (a) the average near surface BSOA mass concentration and (b) its change due to the afforestation during the episodes.

Figure S7 Horizontal distributions of (a) planetary boundary layer height (PBLH), (c) upward sensible heat flux (HFX) and (e) water vapor mixing ratio (QVAPOR), as well as $(b, d, f)$ corresponding changes caused by the afforestation during the episodes, respectively.

Figure S8 Chinese vegetation regionalization. The BTH and ROI are highlighted with black lines. The data set is provided by Data Center for Resources and Environmental Sciences, Chinese Academy of Sciences (RESDC) (http://www.resdc.cn). 

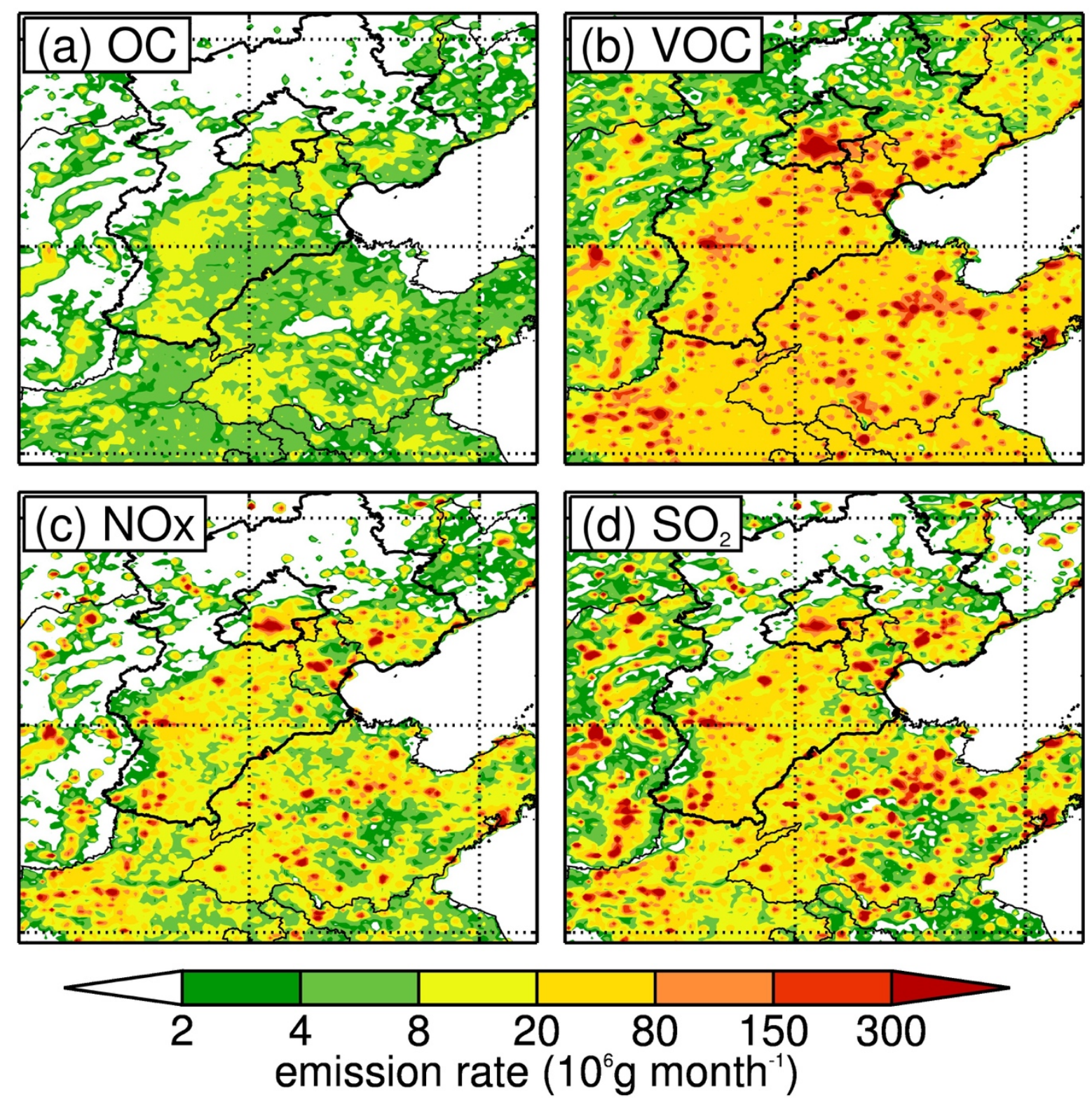

82

83

Figure S1 Spatial distribution of (a) Organic carbon (OC), (b) Volatile organic compound (VOCs), (c) Nitrogen oxide, and (d) Sulfur dioxide $\left(\mathrm{SO}_{2}\right)$ emission rates in December 2013. 

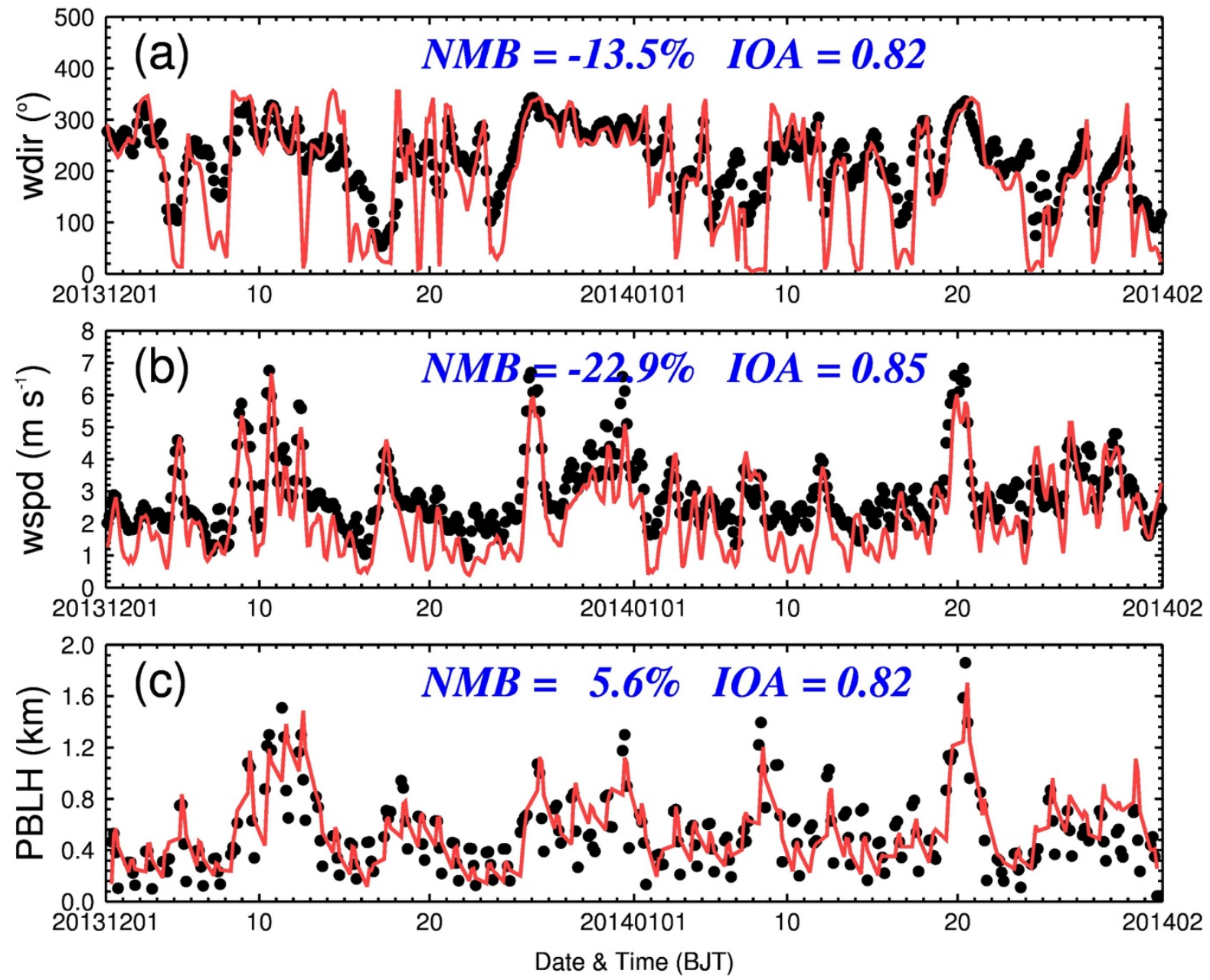

Figure S2 Comparison of the simulated (a) wind direction (wdir), (b) wind speed (wspd), and (c) planetary boundary layer height (PBLH) with the reanalysis data from ECMWF at monitoring sites in BTH from 1 December 2013 to 31 January 2014. The black dots represent the observations, and the red lines denote the reanalysis data. Data are averaged over all monitoring stations in BTH. 

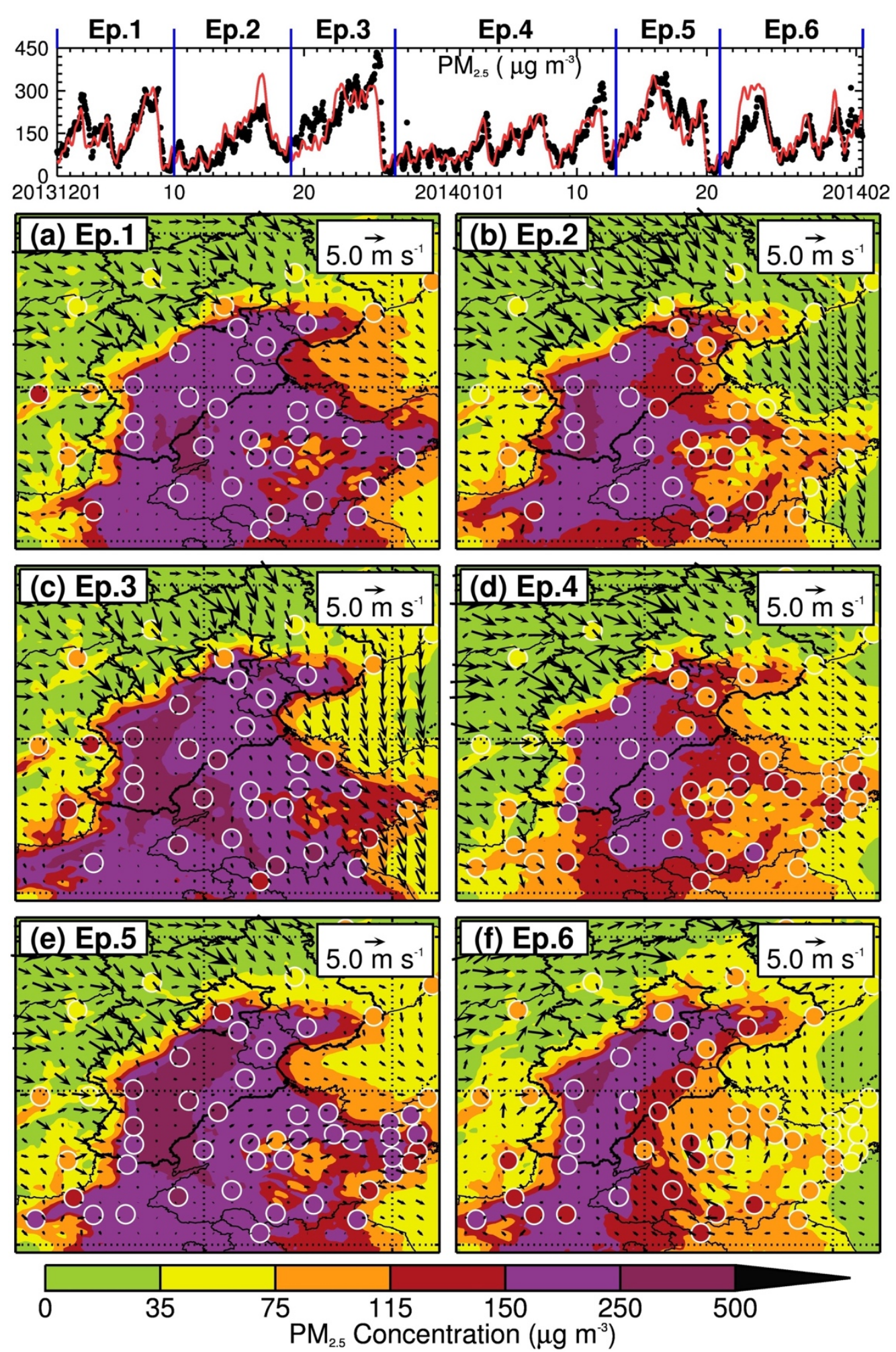

Figure S3 Pattern comparisons of simulated (color counters) vs. observed (colored circles) near-surface $\mathrm{PM}_{2.5}$ mass concentrations averaged during each episode. The black arrows indicate simulated surface winds. 

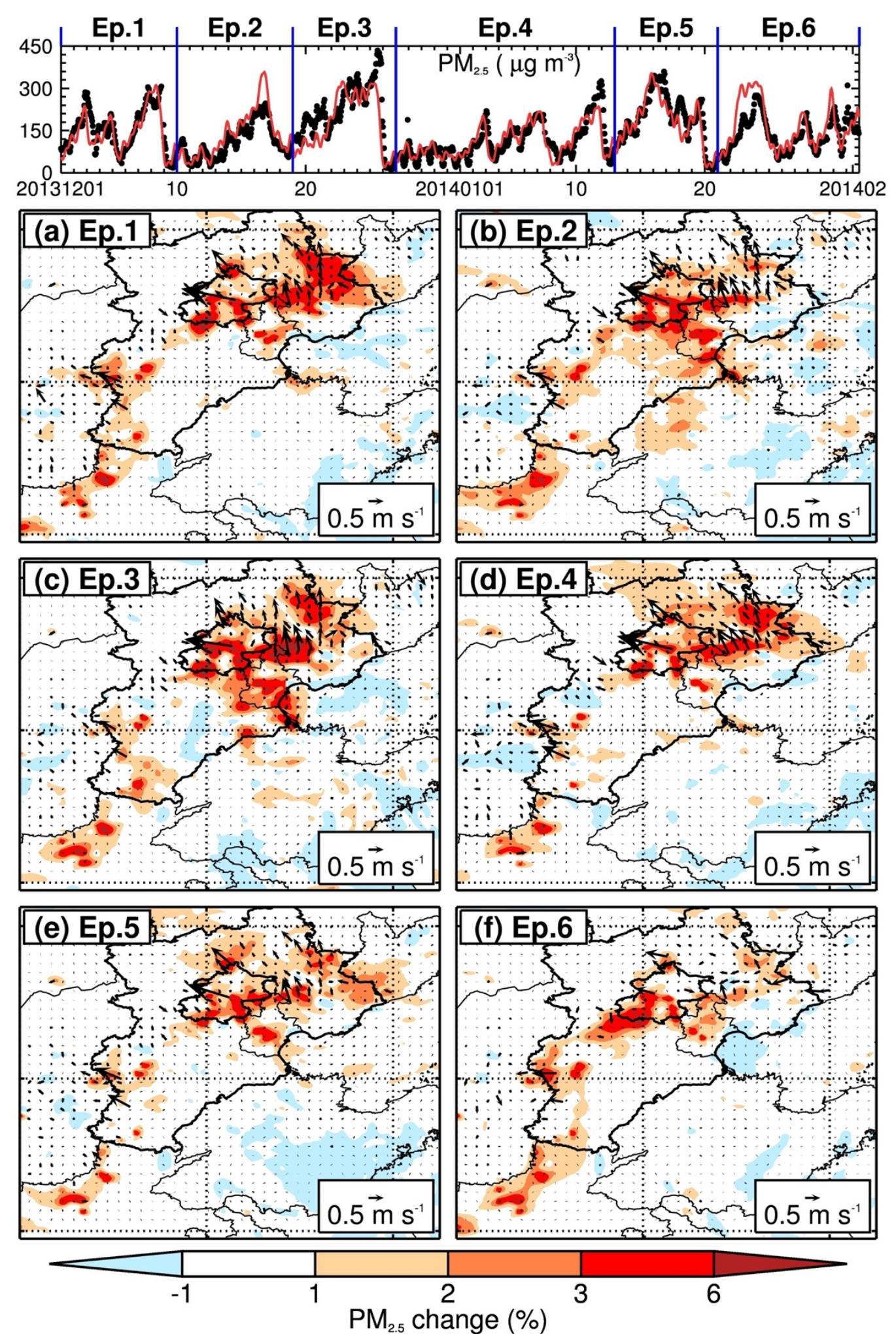

Figure S4 Horizontal distribution of near-surface $\mathrm{PM}_{2.5}$ mass concentration changes caused by the afforestation during each episode. The wind field changes are shown in black arrows. 

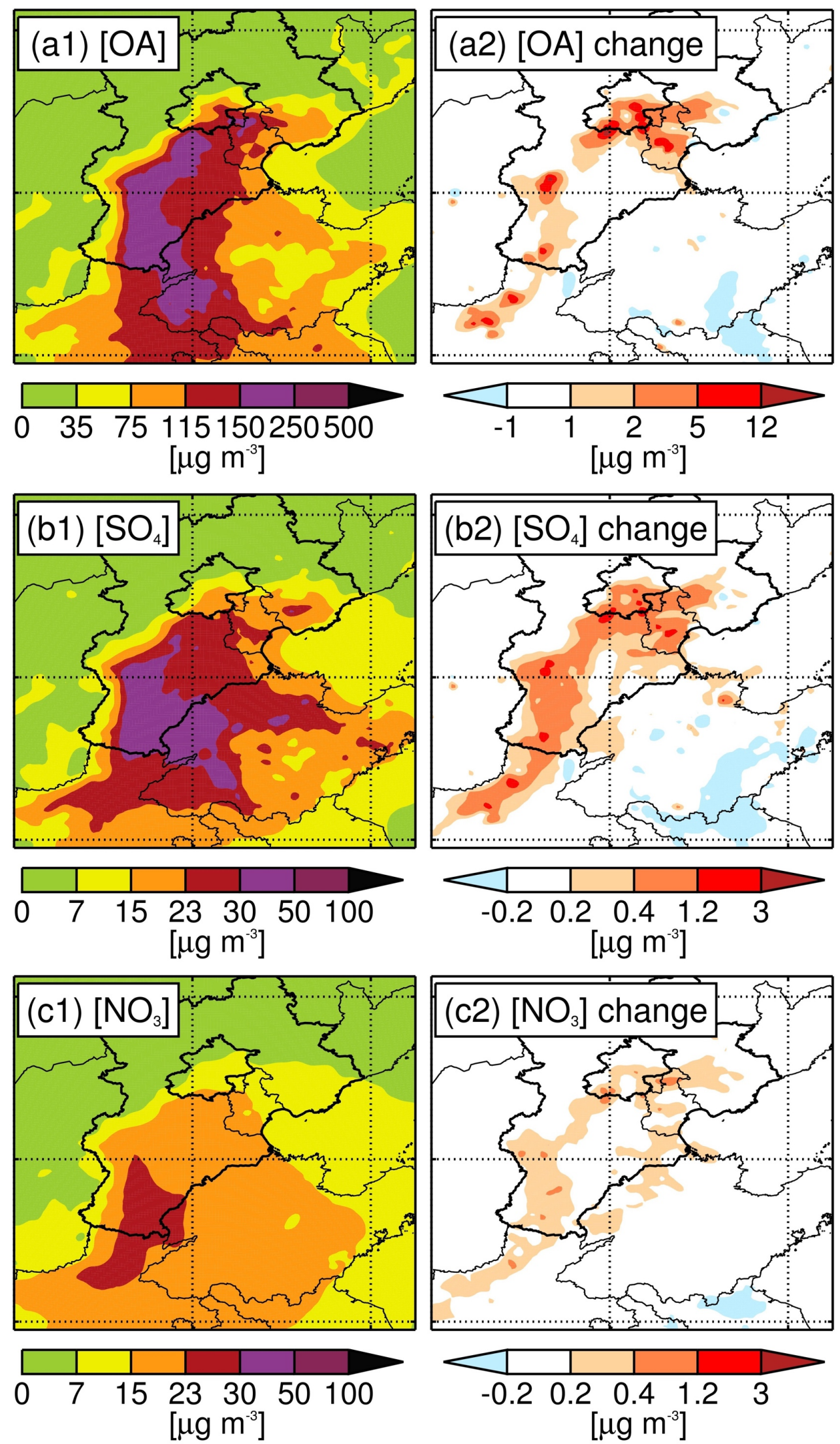

Figure S5 Horizontal distributions of aerosol species mass concentrations and changes due to

114 the afforestation for (a1, a2) organic aerosol (OA), (b1, b2) sulfate $\left(\mathrm{SO}_{4}\right),(\mathrm{c} 1, \mathrm{c} 2)$ nitrate $\left(\mathrm{NO}_{3}\right),(\mathrm{d} 1, \mathrm{~d} 2)$ ammonium $\left(\mathrm{NH}_{4}\right)$, and $(\mathrm{e} 1, \mathrm{e} 2)$ elemental carbon $(\mathrm{EC})$ during the episodes. 

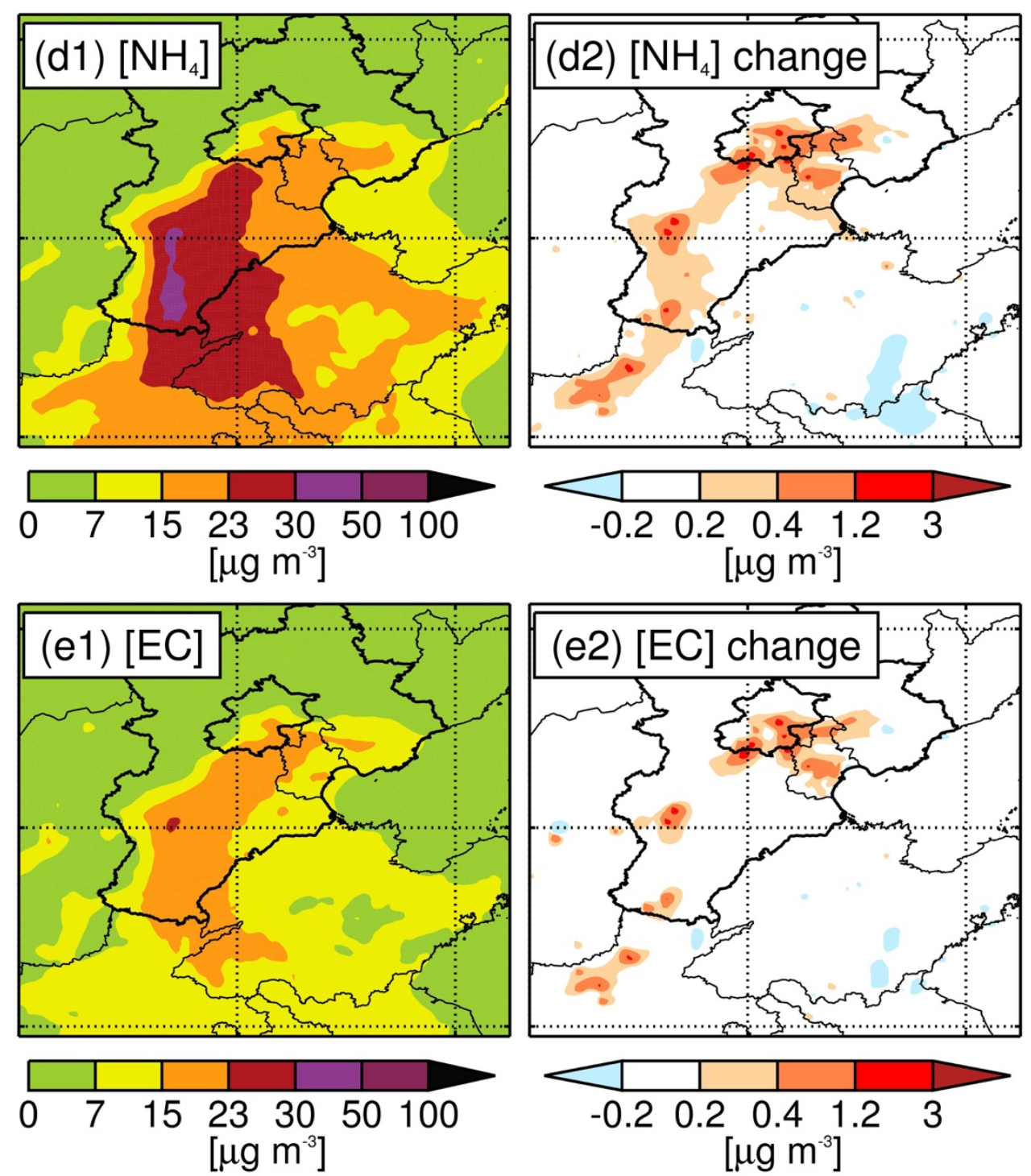

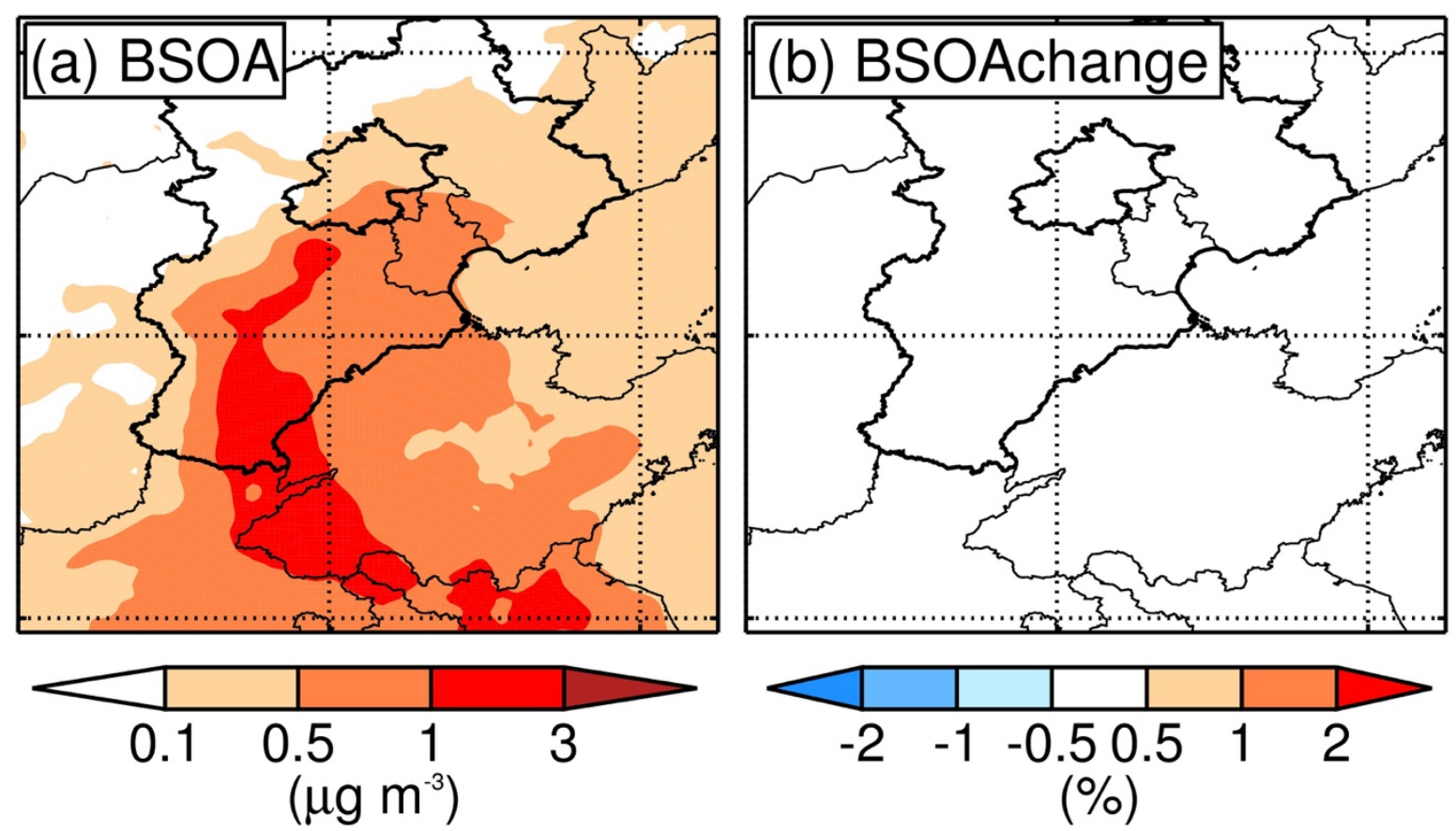

(\%)

Figure S6 Horizontal distributions of (a) the average near surface BSOA mass concentration and (b) its change due to the afforestation during the episodes. 


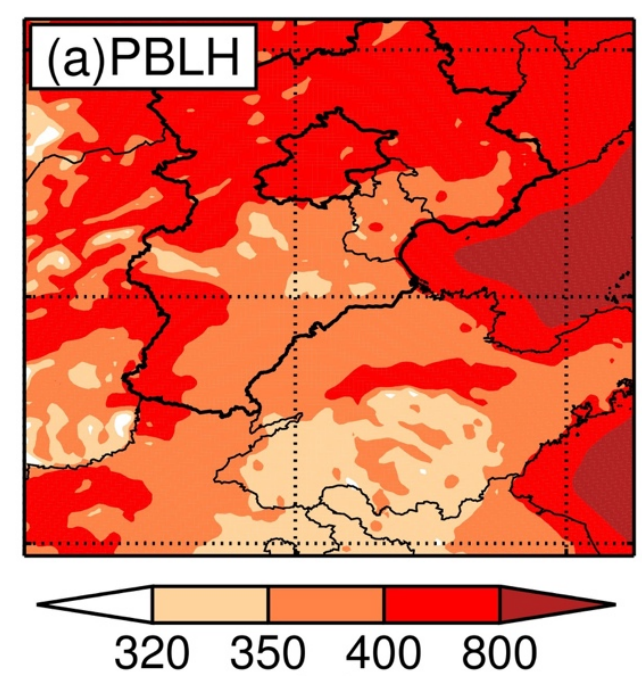

(m)
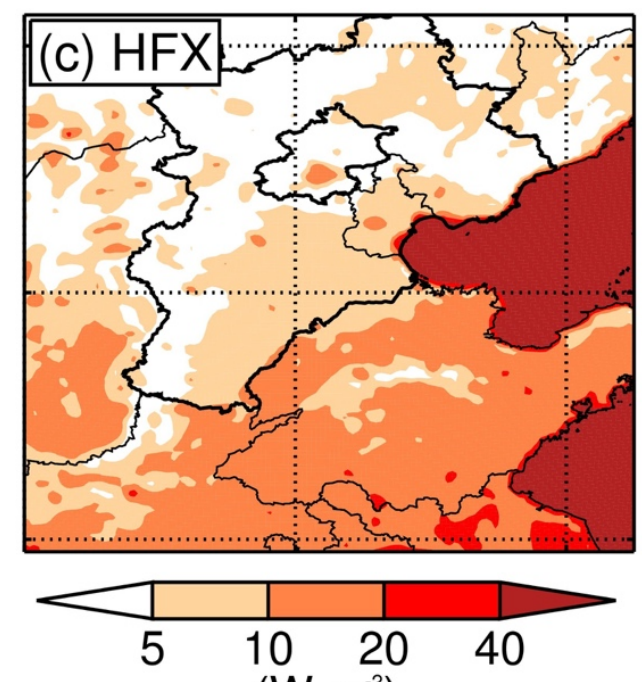

$\left(\mathrm{W} \mathrm{m} \mathrm{m}^{-2}\right)$

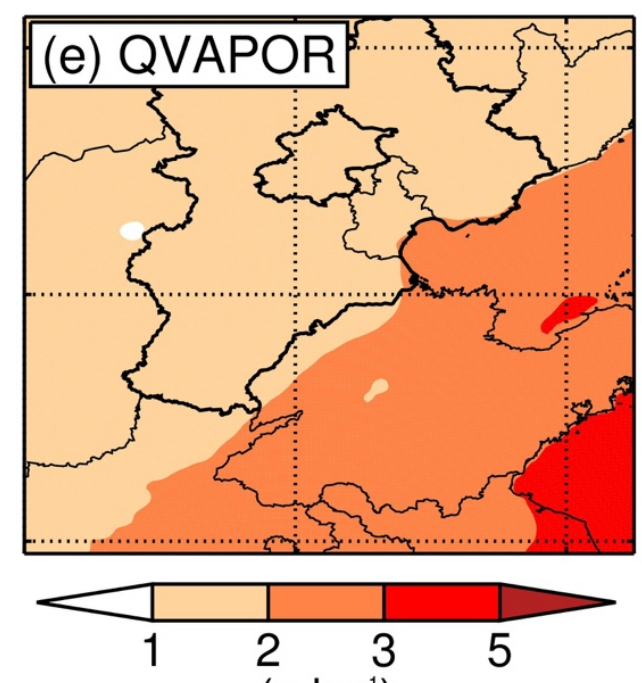

$\left(\mathrm{g} \mathrm{kg}^{-1}\right)$

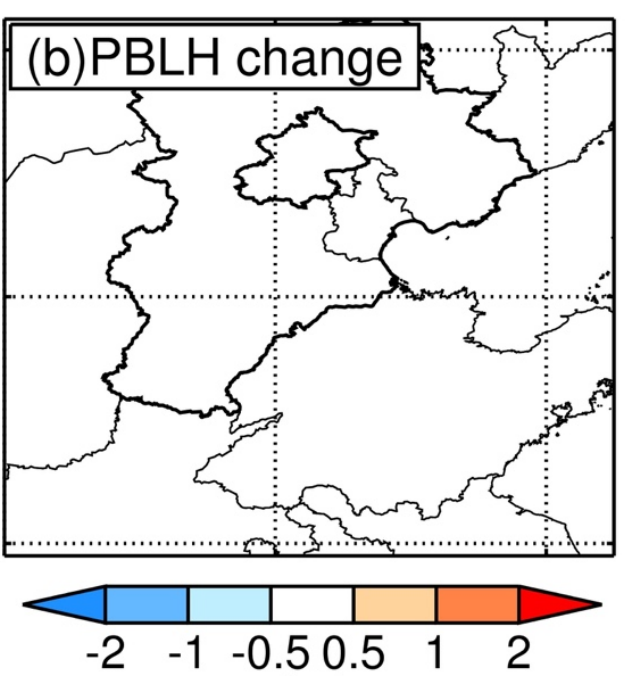

(\%)

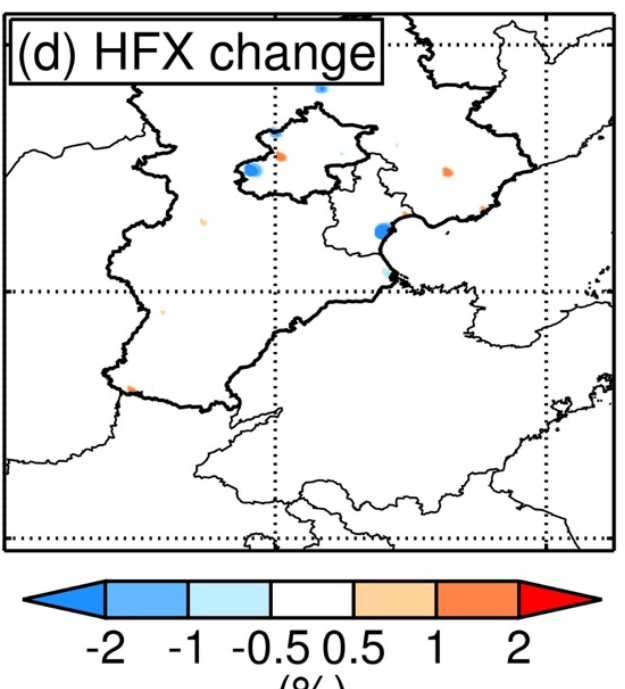

(\%)

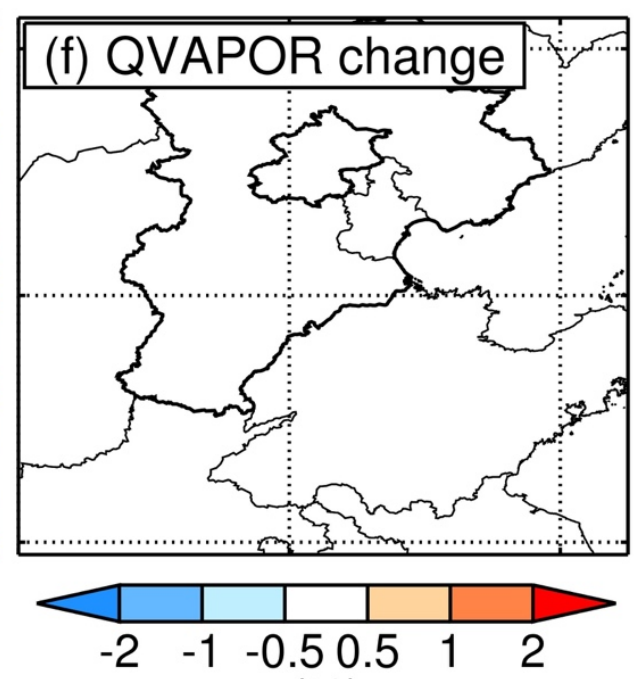

(\%)

Figure S7 Horizontal distributions of (a) planetary boundary layer height (PBLH), (c) upward sensible heat flux (HFX) and (e) water vapor mixing ratio (QVAPOR), as well as (b, d, f) corresponding changes caused by the afforestation during the episodes, respectively.

Figure S10 


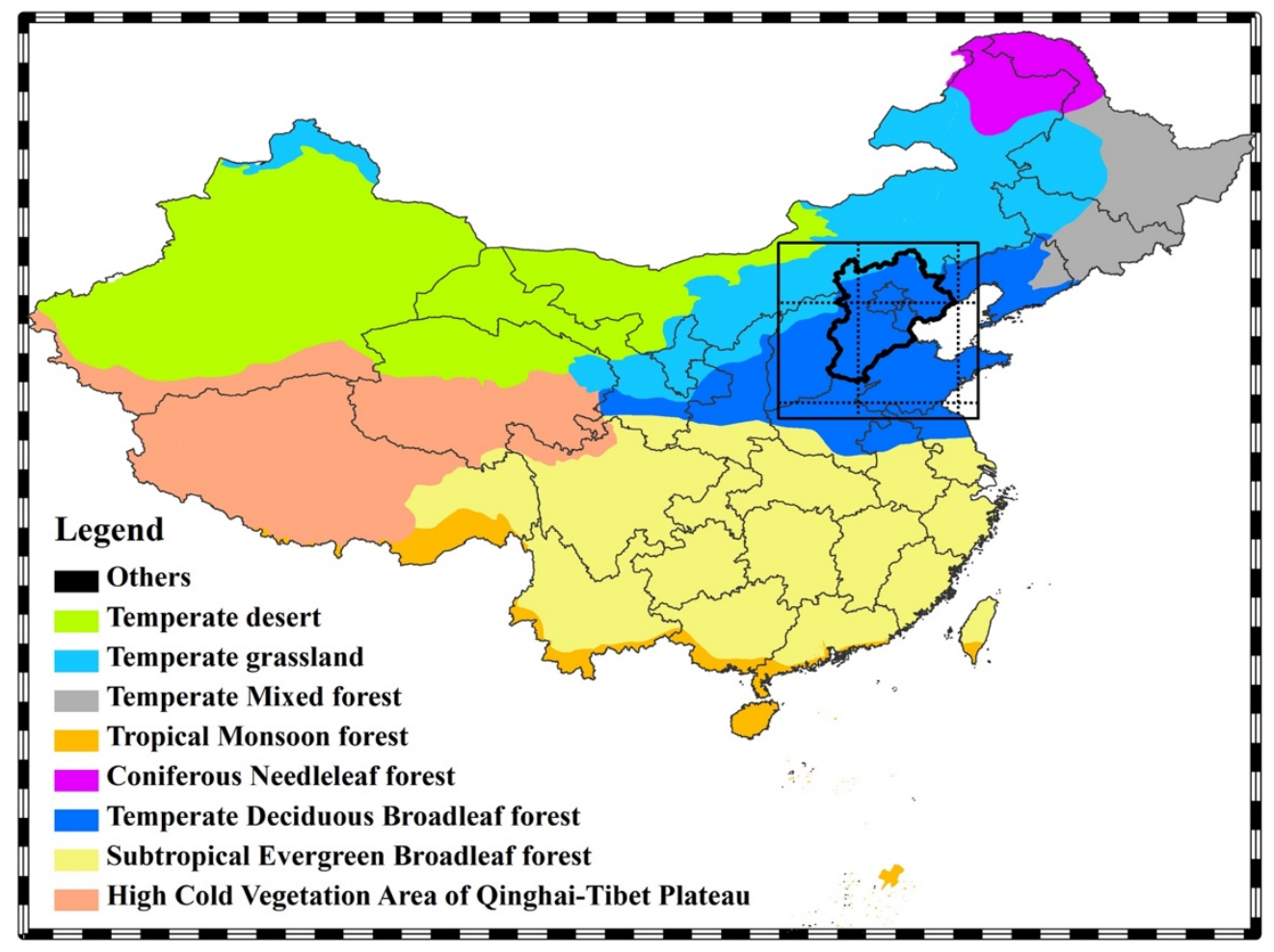

141 Figure S8 Chinese vegetation regionalization. The BTH and ROI are highlighted with black lines. The data set is provided by Data Center for Resources and Environmental Sciences, Chinese Academy of Sciences (RESDC) (http://www.resdc.cn). 